their habitat, in the end resolves itself into sound land management based upon the results of investigation and research. It is generally true to say that land, including almost all grazing land in Africa, is badly managed by human beings. For any area that is well managed to produce high yields on a sustained basis one will see a thousand times that area exploited haphazardly and producing at a fifth of its potential or less. The problem of conflict between man and wild animals has been intensified especially in the last 30 years, by the expansion of the human population, which has not generally been accompanied by an intensification of land use practices - rather the reverse. It can be solved by a rational approach and intelligent land use. But it will not serve mankind to destroy the remaining populations of wild animals by expanding the present generally inefficient systems of land use. In that way he destroys a resource which may be of very great value to him and which may well, in certain areas, be a superior resource to the domestic stock that was all introduced to the continent within comparatively recent historical times.

\title{
Should the Elephants be Killed?
}

$\mathbf{E}^{1}$ LEPHANT populations appear to be out of balance throughout Africa. So far attention has focused mainly on the situation in Uganda's Murchison Falls and Kenya's Tsavo national parks, where elephant damage has been spectacular, but the Kruger park in South Africa also has the problem. In Tsavo and Murchison a build-up in the elephant herds, which are hemmed in by human settlement, agriculture and forestry and unable to emigrate as was once their natural safeguard, has led to destruction of trees and a great increase in the grassland areas. This, coupled with opening up by roads, has resulted in more and severer fires. For the elephants this means a lack of shade and browse, the latter particularly important in the dry season, for without browse they have to rely for food on the grasses just at the time when these are least nutritious, and the elephants then suffer from nutritional deficiencies. These in turn probably cause the lowered fertility of the herds revealed in the longer calving intervals and delayed sexual maturity. These factors, coupled with increased calf mortality ( 38 per cent in the south bank population in Murchison Falls) - which is probably the result of heat stress following the lack of shade and lowered nutrition - are leading to a population crash which in Murchison is well under way and in the Tsavo probably in the early stages.

These are the conclusions of Dr R. M. Laws, who has studied both populations intensively, and I. S. C. Parker, published in a paper Recent Studies on Elephant Populations in East Africa.* The authors suggest that the self-regulatory mechanisms of the elephants for reducing their numbers - longer calving intervals, delayed sexual maturity, increased calf mortality - may have been adequate in the past when coupled with migration to other areas, but today, with the elephants hemmed in by cultivation, they are not sufficient to bring population stability, and the *Symposium of the Zoological Society of London 1968, No 21. 
result is likely to be a population crash that could make the elephants extinct in these parks. They estimate that, without management of the herds, and if present trends continue, the south bank population in Murchison will be down to 22 per cent of the 1945 population by the year 2000; it was already down to 69 per cent in 1965 . Unless man intervenes to accelerate the population crash (which otherwise, owing to the longevity of elephants, will be spread over a long period bringing further damage), 'not only will the diversity of habitats be seriously reduced, but also these populations (and associated populations of other species) may become very small, even extinct, in sanctuaries set aside expressly for their use'.

Other scientists hold different views of the problem, among them Dr A. M. Harthoorn, of Nairobi, eminent in African conservation, particularly in the use of drugs for translocating wild animals, and Dr John Goddard, working at the Tsavo Research Project of which Dr Laws was the first Director. Dr Harthoorn puts the view that elephant herds should not be substantially reduced until research has proved the absolute necessity for it, and in particular has shown the part played by fire in the habitat damage. Cropping, he suggests, is not the simple panacea for over-population. 'The ecological interaction of plant and animal life is a highly complicated meshing of innumerable systems. It is only too easy to do immeasurable harm'. Dr Goddard suggests that a large-scale reduction of the herds could result in a marked increase in the reproductive potential of the survivors, a view which Dr Laws's findings on the elephants' selfregulatory mechanisms as a result of over-population clearly support. Dr Goddard suggests that the important question is whether the habitat changes are deleterious to the fauna of the park as a whole. In the Tsavo the increase in grassland areas has been followed by a marked increase in the animals that favour this habitat: zebra, kongoni, fringe-eared oryx and buffalo, which in the long run must increase the predators on these species - lion, cheetah, hunting dog. And if in a national park the desirable aim is the greatest variety of fauna then this may be no bad thing.

In the meantime the research in the Tsavo is continuing, and we hope to publish an account of it in an early issue of ORYX. Dr Laws is working on the results of his research in the Tsavo and further papers will be published.

\section{Destruction in Hawaii}

TN the last 150 years in the Hawaiian Islands, 24 species of birds have become

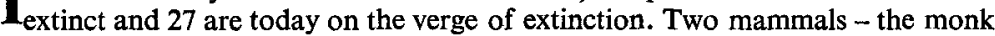
seal and the hoary bat - are also endangered. And the US Bureau of Sport Fisheries and Wildlife describes the situation as 'bad-getting worse' in a 20-page booklet, attractively produced and profusely illustrated, showing (very briefiy) how this has happened and what is being done about it. Until recently the number of bird extinctions was believed to be 26 , but two have been rediscovered - the Maui nukupuu, by Winston E. Banko, a Bureau research scientist, in 1967, and the Molokai creeper. The Bureau holds out little hope of any more being rediscovered. Further information can be had from the Bureau, PO Box 698, Kailua, Hawaii 96734. 